\title{
TGF $\beta$, Activina e Sinalização SMAD em Câncer de Tiróide
}

\section{RESUMO}

TGF $\beta$ e activina são membros da superfamília TGF $\beta$ e desempenham um amplo papel no desenvolvimento, proliferação e apoptose. Estes fatores de crescimento exercem seus efeitos biológicos ligando-se a receptores de membrana do tipo I e do tipo II que transduzem a sinalização até o núcleo através da fosforilação das proteínas R-SMADs (SMAD 2/3) e co-SMADs (SMAD4). O controle apropriado da via de TGF $\beta$ /activina ainda depende da regulação negativa exercida pelo SMAD inibitório (SMAD7) e pelas enzimas E3 de ubiquitinação (Smurfs). Fisiologicamente, TGF $\beta$ e activina atuam como potentes inibidores da proliferação na célula folicular tiroidiana. Desta forma, alterações de receptores e componentes da via de sinalização SMAD estão associadas a diferentes tipos de tumores. Desde que TGF $\beta$ e activina geram sua sinalização intracelular utilizando os mesmos componentes da via SMAD, o desequilíbrio desta via prejudica dois processos antimitogênicos da célula. Nesta revisão, enfocamos aspectos que indicam o mecanismo de resistência ao efeito inibitório de TGF $\beta$ e activina ocasionado pelo desequilíbrio da via de sinalização SMAD nas neoplasias da tiróide. (Arq Bras Endocrinol Metab 2007;51/5:683-689)

Descritores: TGF $\beta$; Activina; Câncer de tiróide; Sinalização SMAD; Smurf; Progressão tumoral

\section{ABSTRACT}

TGF $\beta$, Activin and SMAD Signalling in Thyroid Cancer.

TGF $\beta$ and activin are members of the TGF $\beta$ superfamily and play a wide role in development, proliferation and apoptosis. These growth factors exert their biological effects by binding to the type I and II membrane receptors to transduce their signalling through the nucleus by phosphorylation of R-SMADs (SMAD 2/3) and co-SMADs (Smad 4). The proper control of TGF $\beta$ /activin pathway is negatively regulated by inhibitory SMAD (SMAD7) and by E3 ubiquitination enzymes (Smurfs). Physiologically, TGF $\beta$ and activin act as potent growth inhibitors in thyroid follicular cell. Thus, alterations in the receptors and components of SMAD signalling pathway are associated with several types of tumors. Since TGF $\beta$ and activin generate their intracellular signalling through the same components of the SMAD pathway, the unbalance of this pathway impairs both of anti-mitogenic signals in the cell. This review addresses aspects of the molecular mechanisms in the understanding of resistance to the growth inhibitory effects of TGF $\beta$ and activin due to the disequilibrium in the SMAD inhibitory pathway in thyroid neoplasia. (Arq Bras Endocrinol Metab 2007;51/5:683-689)

Keywords: TGF $\beta$; Activin; Thyroid cancer; SMAD signalling; Smurf; Tumor progression

\section{revisão}

\author{
EDNA T. KIMURA \\ SÍLVIA E. MATSUO \\ JÚlIO CÉzAR RICARTE-FILHO
}

Departamento de Biologia

Celular e do Desenvolvimento, Instituto de Ciências Biomédicas, Universidade de São Paulo, SP.
Recebido em 29/05/07 Aceito em 29/05/07 
$\mathrm{O}$ MEMBROS DA SUPERFAMÍlia TGF $\beta$ (do inglês transforming growth factor $\beta$ ), que incluem TGF $\beta$ e activina, são fatores de crescimento que promovem diferentes respostas biológicas ligando-se a dois pares de receptores de membranas do tipo I e do tipo II e ativando uma sinalização intracelular mediada pelas proteínas SMADs. Cada ligante tem afinidade a receptores específicos dos tipos I e II, que propagam a sinalização através da fosforilação de um conjunto de proteínas SMADs no citoplasma. Uma vez fosforiladas, essas proteínas são levadas ao núcleo, onde ativam ou reprimem a transcrição de diferentes genes-alvos (1). Essa via de sinalização ainda é modulada negativamente por um complexo mecanismo que inclui o SMAD inibitório e as enzimas E3 da via de proteólise mediada por ubiquitina $(2,3)$. A sinalização TGF $\beta$, além de estar envolvida em diferentes processos biológicos durante o desenvolvimento embrionário, exerce diversas funções na homeostase tecidual do organismo adulto. Na célula normal existe um delicado equilíbrio na regulação negativa e positiva de proliferação determinando um ciclo celular normal. No câncer, essa homeostase fica alterada pelo aumento do sinal estimulátorio (oncogene e agentes mitogênicos), ou pela diminuição dos sinais inibitórios (supressor tumoral e indutores de apoptose) (4). Em geral, nas células de origem epitelial, TGF $\beta$ e activina agem como "supressores tumorais", impedindo a progressão do ciclo celular. Alterações dos componentes da via da sinalização TGF $\beta$ são observadas em uma ampla gama de tumores humanos.

\section{MEMBROS DA SUPER FAMÍLIA TGF $\beta$ : TGF $\beta$ E ACTIVINA}

TGF $\beta$ é o protótipo da superfamília de TGF $\beta$ e foi descoberto em 1982, como uma fração adicional ao TGF $\alpha$ secretado por fibroblastos transfectados com oncogenes, e que isoladamente era capaz de conferir "transformação" de colônias de fibroblastos renais de rato (5). No entanto, a principal característica de TGF $\beta$, como um potente fator inibitório em diferentes tipos celulares, mais predominantemente em célula de origem epitelial, foi observada posteriormente (6). Nos mamíferos existem três isoformas de TGF $\beta$ : TGF $\beta 1$, TGF $\beta 2$ e TGF $\beta 3$. Apesar de compartilharem homologia de cerca de $70 \%$ na seqüência de aminoácidos, os genes de TGF $\beta 1$, TGF $\beta 2$ e TGF $\beta 3$ estão localizados em regiões distintas dos cromossomos humanos 19q13, lq41 e 14q24, respectivamente. TGF $\beta 1$ é secretada sob a forma de um complexo latente, o qual é incapaz de interagir com seu receptor, portanto é biologicamente inativo. Ao ser clivado, esse complexo libera TGF $\beta 1$ como uma proteína homodimérica ativa de $25 \mathrm{kDa}$, com sub-unidades de 112 aminoácidos (7).

Diversas proteínas que se assemelham estruturalmente a TGF $\beta$, com presença de 7 resíduos de cisteínas altamente conservados, passaram a integrar a superfamília de TGF $\beta$, entre elas activinas, bone morphogenetic protein (BMP), growth differentiation factor (GDF), glial cell line-derived neurotrophic factor (GDNF), müllerian inbibiting substance (MIS) e inibinas (1). As activinas são os membros desta superfamília que possuem características mais próximas às dos peptídeos TGF $\beta$. Foram originalmente isoladas de ovário de porco e identificadas pela sua habilidade em estimular a secreção do hormônio folículo estimulante (FSH) em cultura de células hipofisárias $(8,9)$. As activinas são proteínas diméricas de $28 \mathrm{kDa}$, constituídas por 2 sub-unidades $\beta$ de 116 aminoácidos conectadas por ponte dissulfídrica. Até o momento, foram descritas 5 sub-unidades $\beta$ das activinas $(\beta \mathrm{A}, \beta \mathrm{B}, \beta \mathrm{C}, \beta \mathrm{D}$ e $\beta \mathrm{E})$. Todas as sub-unidades, com exceção da $\beta \mathrm{D}$, foram isoladas em mamíferos, sendo as sub-unidades $\beta \mathrm{A}, \beta \mathrm{B}$ e $\beta C$ identificadas em humanos. A combinação homo ou heterodimérica forma as diferentes isoformas das activinas: activina $\mathrm{A}(\beta \mathrm{A} \beta \mathrm{A})$, activina $\mathrm{B}(\beta \mathrm{B} \beta \mathrm{B})$, activina $\mathrm{AB}(\beta \mathrm{A} \beta \mathrm{B})$ etc. As sub-unidades $\beta \mathrm{A}$ e $\beta \mathrm{B}$ de activinas apresentam $85 \%$ de homologia entre si, contudo o gene $\beta A$ está localizado no cromossomo 7 humano, enquanto o gene de $\beta \mathrm{B}$ está localizado próximo ao centrômero do braço curto do cromossomo 2 (10).

\section{SINALIZAÇÃO DE TGFB/ACTIVINA PELA VIA DE PROTEÍNAS SMADS}

A ação tanto de TGF $\beta$ como de activina se inicia com a ligação de cada um destes fatores a uma combinação de receptores de membrana específicos dos tipos I e II com atividade serina-treonina quinase. TGF $\beta$ liga-se ao seu receptor tipo II específico, T $\beta$ RII, o qual fosforila e ativa o receptor tipo I, T $\beta R I$. O receptor tipo I propaga a sinalização através da ativação e fosforilação de proteínas citoplasmáticas da família de SMADs conhecidas como receptor-regulated SMADs (R-SMADs), SMAD2 e SMAD3. A fosforilação de RSMADs permite a sua interação com commonmediator SMAD (co-SMAD), SMAD4, formando um complexo capaz de atingir o núcleo, onde irão modular a transcrição de genes-alvos (1) (figura l). A activina, por sua vez, liga-se ao receptor tipo II 
(ActRII ou ActRIIB) e este recruta o receptor tipo I. Dentre as isoformas de ActRI, o receptor ActRIB propaga a sinalização intracelular de activina pela ativação de SMADs $2 / 3$ e 4 da mesma forma como ocorre na sinalização de TGF $\beta$ (10) (figura 1). A sinalização SMAD é atenuada por SMAD7, uma SMAD inibitória (I-Smad) que previne a fosforilação de R-SMAD e interfere na formação do complexo R-SMAD com CoSMAD (2). BMP, outro membro da superfamília de TGF $\beta$, é bem conhecido pelos seus efeitos na formação óssea. De modo similar à sinalização de TGF $\beta$ e activina, BMP atua através de seus receptores específicos e induz sinalização intracelular via R-SMADs, SMADI, SMAD5 e SMAD8, as quais se associam à co-SMAD, SMAD4. Esse complexo se move ao núcleo para modular a transcrição de genes-alvos de BMP. SMAD6 é a SMAD inibitória para sinalização de BMP. Assim, SMAD4 além de participar da sinalização TGF $\beta$ e activina, é uma mediadora comum para outros membros da superfamília de TGF $\beta$. Por outro lado, SMAD2 e SMAD3 são exclusivas da sinalização de TGF $\beta$ e activina (1).

As SMADs são constituídas por domínios conservados, amino-terminal (MHl) e carboxi-terminal (MH2), e um domínio central pouco conservado que conecta domínios $\mathrm{MHl}$ e $\mathrm{MH} 2$ (figura 2). O domínio $\mathrm{MHl}$ confere às SMADs capacidade de associação com

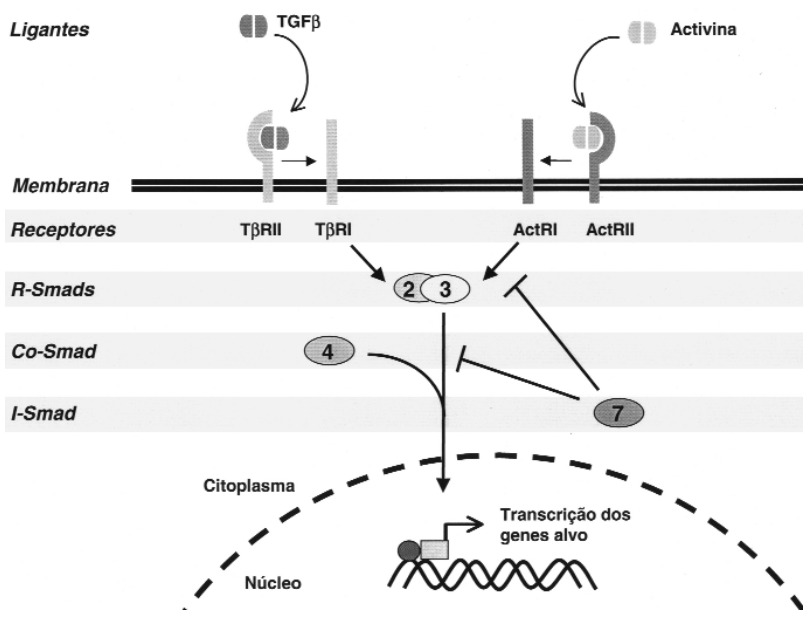

Figura 1. Esquema da sinalização celular de TGF $\beta$ e de activina. TGF $\beta$ se liga ao seu receptor de membrana tipo II (TßRII), o qual recruta e ativa o receptor tipo I (TßRI). A activina, por sua vez, se liga ao seu receptor tipo II (ActRII), que irá ativar o receptor tipo I (ActRI). A sinalização intracelular é propagada através de proteínas SMADs, sendo que SMAD2 e SMAD3 são fosforiladas e ativadas pelos receptores tipo I. A SMAD4 se une à SMAD2/3 fosforilada e este complexo modula a transcrição de genes-alvos no núcleo. A SMAD 7 inibe a sinalização de TGFß/activina. o DNA e interação com fatores de transcrição, enquanto MH2 é importante para formação do complexo SMAD-receptor e confere atividade transcricional (11). Embora SMAD2 e SMAD3 compartilhem alta homologia e ambas sejam capazes de responder ao estímulo gerado pelo complexo TGF $\beta /$ receptor ou activina/receptor, existem diferenças funcionais entre as R-SMADs, que poderiam ser explicadas em parte pela capacidade de a SMAD3 se ligar ao DNA, enquanto a SMAD2 apresenta um inserto em seu domínio MHI que impede sua interação com o DNA $(1,11)$.

\section{AÇÃO BIOLÓGICA DE TGFß E ACTIVINA}

Uma diversidade de processos biológicos tem sido atribuída a TGF $\beta$ e activina, incluindo controle da proliferação e diferenciação celular, apoptose, desenvolvimento embrionário, função endócrina e reparo tecidual. Muitos desses conhecimentos foram adquiridos pelos estudos de TGF $\beta 1$ e activina $A$, as isoformas mais exploradas de cada família. Embora TGF $\beta$ e activinas desencadeiem sinalização através de mediadores intracelulares comuns, representadas pelas SMADs $2 / 3$ e 4 , essas proteínas podem induzir respostas biológicas específicas. No desenvolvimento embrionário, fica evidente o papel distinto exercido por cada membro da superfamília com a geração de camundongos knockout de TGF $\beta 1$ e de activina A. Esses estudos revelam que a maioria dos camundongos homozigotos para TGF $\beta 1$ morre durante a embriogênese, e os que sobrevivem desenvolvem infiltrado inflamatório em múltiplos órgãos. Camundongos knockout para activina $\mathrm{A}$, por sua vez, apresentam defeitos craniofaciais e morrem no período perinatal por dificuldade de sucção (12). Esses modelos de knockout sugerem que a ausência de um

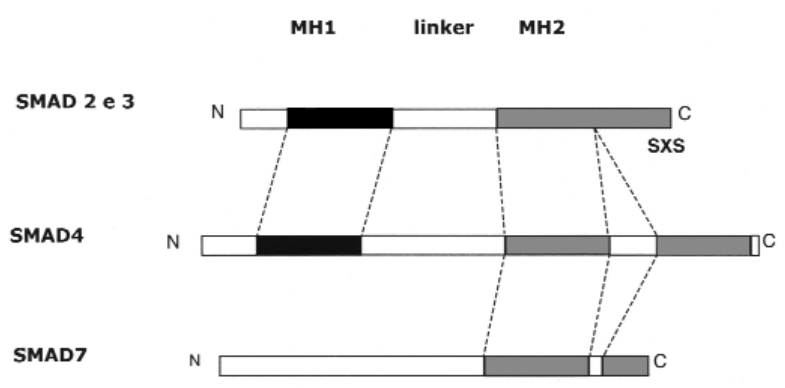

Figura 2. Família de SMAD. Esquema da estrutura de RSMADs (SMAD1, SMAD2, SMAD3, SMAD5 e SMAD8), coSMAD (SMAD4) e I-SMAD (SMAD6 e SMAD7). O domínio $\mathrm{MH} 1$ está representado em preto e o domínio MH2 em cinza. SXS corresponde ao sítio de fosforilação de R-SMADs pelo receptor tipo I. 
dos membros da superfamília não é compensada por outro, mesmo que a via comum de sinalização por SMADs esteja íntegra, reforçando a especificidade e a independência dos efeitos desencadeados por cada fator de crescimento.

Apesar da sua definição original "transformante", TGF $\beta 1$ é mais conhecido como um potente inibidor da proliferação de células epiteliais, incluindo hepatócitos, células pulmonares, intestinais, prostáticas e mamárias (6). TGF $\beta$ promove a interrupção da progressão do ciclo celular, na fase G1, pela indução de pl5 e p21, proteínas conhecidas como inibidoras de CDKs (do inglês cyclindependent kinases), prevenindo a hiperfosforilação da proteína do retinoblastoma $(\mathrm{pRB})$ e pela supressão de $\mathrm{c}$ MYC $(13,14)$. Por outro lado, na matriz extra-celular TGF $\beta$ estimula a angiogênese, inibe o sistema imune e propicia um ambiente favorável para a migração da célula tumoral e metástase (15).

A activina estimula a proliferação de células ovarianas e testiculares $(16,17)$, mas exerce efeito inibitório em diversas outras células de origem epitelial, tais como hepáticas, prostáticas, mamárias, hipofisárias e adrenais (18). Os mecanismos pelos quais a activina exerce seus efeitos inibitórios são menos conhecidos, mas reconhecese um aumento de p15 e p21, redução dos níveis de CDK4 e hipofosforilação de $\mathrm{Rb}$ em diferentes tipos celulares de maneira semelhante ao observado na ação anti-proliferativa de TGF $\beta(19,20)$. Por outro lado, ao contrário de TGF $\beta$ que estimula a angiogênese, a activina reduz a neovascularização (18).

\section{TGFß E ACTIVINA NO CÂNCER}

Embora, o papel proliferativo de activinas ainda permaneça controverso em alguns sistemas, o efeito inibitório exercido por TGF $\beta$ e pelas activinas e a integridade da sinalização por eles gerada parece ter um papel muito importante na manutenção da homeostase celular. Alterações na sinalização de TGF $\beta$ / activinas que bloqueiam o efeito inibitório exercido por esses fatores podem contribuir na evolução tumoral (21). Existem relatos de que, durante a progressão tumoral, o TGF $\beta$ deixa de exercer um papel anti-proliferativo e inverteria o seu papel estimulando a proliferação da célula tumoral, como observado no estadio avançado de câncer de mama e de câncer de cabeça e pescoço $(15,22,23)$.

Inativação de receptores I e/ou II de TGF $\beta$ ou de activinas e de SMADs foi associada a tumores de diversos tecidos, tais como tumores pancreáticos, gástricos, de mama e cólon (24). Embora o mecanismo não esteja estabelecido, estudos epidemiológicos indicam que o polimorfismo TGFBRI * 6 A no gene do receptor tipo I de TGF $\beta$ possa atuar como alelo de susceptibilidade tumoral em câncer de mama e ovário (25). Em metástase de carcinoma de cólon ocorre uma alta freqüência de polimorfismo TGFBRl * 6 adquirido somaticamente (26).

Os genes de SMAD2 e SMAD4 estão localizados no cromossomo $18 \mathrm{q} 21$ humano, uma região com alta freqüência de mutações, enquanto o gene de SMAD3 está localizado no cromossomo 15q21-22. SMAD4 foi originalmente descrito como deleted in pancreatic cancer locus 4 (DPC4), pela alta incidência desta deleção em câncer pancreático (27) e, posteriormente, observou-se que mutação de Smad4 também estava presente em tumores coloretais, gástricos, hepáticos e de pulmão $(24,28)$. Em tiróide, alterações genéticas que incluem deleções e alterações de splicing no gene de SMAD4 foram observadas em 27\% dos tumores benignos e malignos (29). Mutações no gene que codifica SMAD2 são encontradas em tumores de fígado, colo-retal e pulmão (24). Curiosamente, a mutação do gene de SMAD3 está pouco associada ao desenvolvimento de tumores humanos, embora camundongo knockout para o gene de SMAD3 desenvolva um câncer colo-retal agressivo (30).

\section{TGF $\beta$ E ACTIVINA NA TIRÓIDE}

Desde a sua caracterização, há cerca de duas décadas, o papel de TGF $\beta$ na célula folicular tem sido estudado extensivamente. A célula tiroidiana não-neoplásica responde à adição de TGF $\beta$ exibindo um efeito duplo, inibindo a proliferação celular e a função tiroidiana (3133). TGF $\beta$ promove a diminuição da expressão dos genes de diferenciação tiroidiana tireoglobulina, NIS e TPO $(34,35)$. Há mais de meio século, reconhece-se o papel inibitório do iodo na tiróide, conhecido como efeito auto-regulatório do iodo. O TGF $\beta$ teria um papel importante na ação antimitogênica do iodo, desde que o iodo induz a expressão de TGF $\beta$ na célula folicular $(36,37)$. Em células tiroidianas neoplásicas, a resposta ao TGF $\beta$ em linhagem celular tem sido consistentemente anti-proliferativa, como observado em diferentes linhagens de carcinoma papilífero (NPA, BHP, FTC133 e de PTC-UC3) (38-40). No entanto, em cultura primária oriunda de bócios ou de carcinoma, a resposta ao TGF $\beta 1$ é extremamente variável, indicando uma refratariedade destas células ao TGF $\beta$ (33).

O papel da activina na proliferação da célula folicular é ambíguo. Enquanto uns atribuem um efeito 
inibitório desta molécula, outros indicam que ele seja estimulatório em células neoplásicas e não-neoplásicas da tiróide $(41,42)$. Em cultura primária de carcinoma papilífero de tiróide, a adição de activina $\mathrm{A}$ não alterou a proliferação em 3 de 4 carcinomas estudados, enquanto induziu aumento da proliferação em um carcinoma (43). Utilizando método de RNA de interferência mostramos recentemente que o bloqueio do gene de activina em linhagem de carcinoma papilífero TPC-1 de tiróide promove aumento da proliferação, de forma semelhante ao observado com o bloqueio do gene de TGF $\beta$, indicando que ambos exercem ação antiproliferativa nesta linhagem de carcinoma tiróide (44).

Pelo fato de TGF $\beta$ ser um fator inibitório para a proliferação de células epiteliais, com característica de supressor tumoral, esperava-se observar uma falência na expressão desta proteína no câncer em geral. No entanto, a expressão gênica e/ou protéica de TGF $\beta$ está geralmente aumentada em cânceres derivados de células epiteliais, tais como câncer de pâncreas, cólon, estômago e de mama, sugerindo escape das células tumorais ao efeito antimitogênico de TGF $\beta$ (21). Em tecido tiroidiano normal, a expressão de TGF $\beta$ na célula folicular é tênue, no entanto as células foliculares de lesões tumorais da tiróide apresentam expressão marcante das diferentes isoformas de TGF $\beta$, TGF $\beta 1$, TGF $\beta 2$ e TGF $\beta 3$, tanto em nódulos benignos quanto em carcinomas (45). Um padrão de expressão de activinas $\beta \mathrm{A}$ e $\beta \mathrm{B}$ semelhante à expressão de TGF $\beta$ é observado em tumores tiroidianos (46). A expressão de receptores tipos I e II de TGF $\beta$ e de activina está presente em tumores de tiróide, indicando que TGF $\beta$ s e activinas atuam de forma autócrina/parácrina nesta glândula; assim como a expressão de $\mathrm{SMAD} 2 / 3$ e SMAD4 está presente em lesões benignas e malignas de tiróide $(41,47,48)$.

\section{REGULAÇÃO NEGATIVA DA VIA DE SINALIZAÇẢ̃O SMAD E IMPLICAÇÃO NO CÂNCER DE TIRÓIDE}

\section{SMAD Inibitório}

Além dos SMADs envolvidos na transdução da sinalização intracelular dos ligantes da família TGF $\beta$ ao núcleo, denominados SMADs regulatórios, a via de sinalização de TGF $\beta$ /activina é regulada pelo SMAD7, classificado como SMAD inibitório (ISMAD) (2). O SMAD7 bloqueia a fosforilação dos RSMADs, interferindo na fosforilação de $\mathrm{SMAD} 2 / 3$ pelo receptor tipo I e na formação do complexo RSMAD/Co-SMAD (49) (figura 1).
A transcrição de SMAD7 é induzida por TGF $\beta$ e mediada pela ligação de SMAD3 e SMAD4 na região promotora do SMAD7, representando um mecanismo auto-regulatório da via de sinalização TGF $\beta$ (50). O bloqueio da expressão gênica de activina $\mathrm{A}$ ocasiona diminuição dos níveis de mRNA de SMAD7 em linhagem de carcinoma papilífero TPC- 1 , indicando que a expressão de SMAD7 é regulada não somente por TGF $\beta$, mas também pela activina (44). Na linhagem de carcinoma anaplásico de tiróide ARO, há um aumento na expressão SMAD7 que sugere uma relação da agressividade tumoral com a atenuação da via TGF $\beta$ /activina neste tipo histológico de câncer de tiróide (48).

\section{Enzimas da via de ubiquitinação}

Recentemente, foram identificadas enzimas que regulam a degradação de componentes da via de sinalização de TGF $\beta$ pelo sistema de proteólise dependente de ubiquitinação (51). A ubiquitinação das proteínas vem sendo reconhecida como um importante processo de regulação celular (52). Um crescente número de proteínas relacionadas ao desenvolvimento de câncer participa da via de ubiquitinação, como alvo de degradação proteolítica ou como um dos componentes desta via. A ligação da proteína-alvo à ubiquitina requer a ação seqüencial das enzimas E1, E2 e E3 ligases, sendo que a capacidade de E3 reconhecer a proteína-alvo confere uma alta especificidade ao sistema ubiquitina-proteossoma (53). A identificação das proteínas Smurfl e Smurf2 (do inglês SMAD ubiquitination regulatory factor) e, mais recentemente Arkadia, como E3 ubiquitinaligases associadas à degradação específica de componentes da via sinalização de TGF $\beta$, ampliou o conhecimento do mecanismo de controle intracelular desta via (3). Os Smurfs estão envolvidos na proteólise de SMAD2, SMAD4, SMAD7 e do receptor tipo I, seriam reguladores negativos da sinalização intracelular de SMAD $(54,55)$. Por outro lado, Arkadia, identificada como uma E3 ligante de SMAD7, participa da proteólise de SMAD7, o que leva à sustentação da sinalização TGF $\beta$ /activina na célula (56). A expressão desregulada de E3 ligases, em geral, foi associada ao desenvolvimento de patologias humanas incluindo câncer. Nos tumores de tiróide ocorre uma acentuada expressão de Smurf2 principalmente em carcinoma papilífero (57). O desequilíbrio da via de ubiquinação poderia estar associado à perda de responsividade ao efeito antiproliferativo de TGF $\beta$ (3), comumente observado em diversos tipos de câncer. 


\section{PERSPECTIVAS}

Um importante avanço no entendimento da sinalização TGF $\beta$ /activina foi observado principalmente na última década. Nesta revisão, enfocamos o papel inibitório de TGF $\beta$ /activina no processo proliferativo e neoplásico da tiróide, atuando pela via de sinalização dependente de SMAD. Uma questão importante a ser entendida no câncer é como as células epiteliais tornam-se refratárias à sinalização antiproliferativa dos fatores inibitórios. No carcinoma de tiróide, as evidências de alterações genéticas como mutações e deleções nos componentes desta via de sinalização são raras. Por outro lado, o envolvimento dos reguladores negativos da via SMAD, o SMAD inibitório e as enzimas E3 de proteólise, começam a ser elucidados e poderão esclarecer a refratariedade à ação inibitória de TGF $\beta$ / activina nos tumores de tiróide. Apesar de a via SMAD ser a melhor caracterizada e reconhecida como a principal via de transdução da sinalização da família TGF $\beta$, são crescentes as evidências de que TGF $\beta$ / activina exercem seus efeitos biológicos utilizando outras vias, não-dependentes de SMAD (58). A expansão destes conhecimentos ampliará a complexidade de atuação de TGF $\beta$ e de activina na homeostase celular e na oncogênese da tiróide.
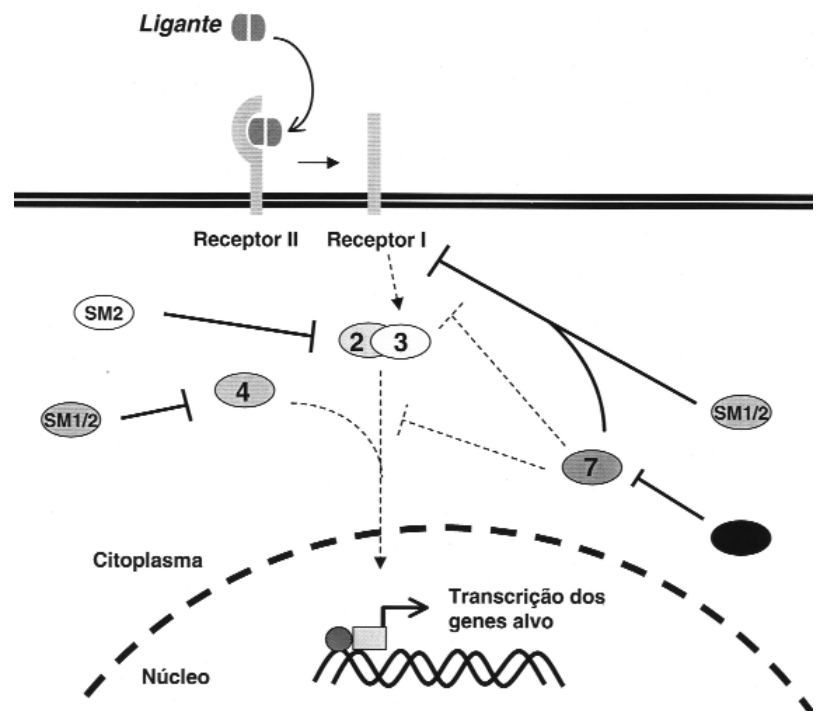

Figura 3. Controle da sinalização TGF $\beta$ /Activina exercida pelas enzimas E3 ubiquitina-ligase Smurf1, Smurf2 e Arkadia. Smurf1 e Smurf2 (SM1/2) atuam como proteínas adaptadoras que recrutam Smad7 ao receptor do tipo I para promover a degradação do complexo Smad7/receptor através de vias proteassômicas. Smurf1 e Smurf2 promovem, ainda, a ubiquitinação de Smad4, e apenas Smurf2 (SM2) é capaz de ubiquitinar Smad2 para degradação. Mostramos, ainda, Arkadia (ARK), uma E3 ligase essencial na ubiquitinação de Smad7 e degradação pelo proteassoma, o que indiretamente amplifica a sinalização de TGF $\beta$.

\section{AGRADECIMENTOS}

À FAPESP, CAPES e CNPq, pelo auxílio financeiro aos projetos de pesquisa que geraram dados apresentados neste trabalho e pelas bolsas de produtividade em pesquisa (ETK) e de doutorado (SEM. e JCR-F).

\section{REFERÊNCIAS}

1. Massague J. TGF $\beta$ signal transduction. Annu Rev Biochem 1998:67:753-91.

2. Heldin $\mathrm{CH}$, Miyazono $\mathrm{K}$, ten Dijke P. TGF $\beta$ signalling from cell membrane to nucleus through SMAD proteins. Nature 1997;390:465-71.

3. Izzi L, Attisano L. Regulation of the TGF $\beta$ signalling pathway by ubiquitin-mediated degradation. Oncogene 2004;23:2071-8.

4. Matsuo SE, Martins L, Leoni SG, Hajjar D, Ricarte-Filho JCM, Ebina KN, et al. Marcadores biológicos de tumores tiroidianos. Arq Bras Endocrinol Metab 2004;48:114-25.

5. Anzano MA, Roberts AB, Meyers CA, Komoriya A, Lamb LC, Smith JM, et al. Synergistic interaction of two classes of transforming growth factors from murine sarcoma cells. Cancer Res 1982;42:4776-8.

6. Massague J, Blain SW, Lo RS. TGF $\beta$ signaling in growth control, cancer, and heritable disorders. Cell 2000;103:295-309.

7. Roberts $A B$, Sporn MB. The transforming growth factor beta. Peptide Growth Factors and their Receptors. Heidelberg: Springer-Verlag, 1990. pp. 419-72.

8. Ling N, Ying SY, Ueno N, Shimasaki S, Esch F, Hotta M, et al. Pituitary FSH is released by a heterodimer of the $\beta$-subunits from the two forms of inhibin. Nature 1986;321:779-82.

9. Vale W, Rivier J, Vaughan J, McClintock R, Corrigan A, Woo $\mathrm{W}$, et al. Purification and characterization of an $\mathrm{FSH}$ releasing protein from porcine ovarian follicular fluid. Nature 1986;321:776-9.

10. Pangas SA, Woodruff TK. Activin signal transduction pathways. Trends Endocrinol Metab 2000;11:309-14.

11. Wrana JL, Attisano L. The Smad pathway. Cytokine Growth Factor Rev 2000;11:5-13.

12. Matzuk MM, Kumar TR, Vassalli A, Bickenbach JR, Roop DR, Jaenisch $R$, et al. Functional analysis of activins during mammalian development. Nature 1995;374:354-6.

13. Geng $Y$, Weinberg RA. Transforming growth factor beta effects on expression of G1 cyclins and cyclin-dependent protein kinases. Proc Natl Acad Sci U S A 1993;90:10315-9.

14. Warner BJ, Blain SW, Seoane J, Massague J. Myc downregulation by transforming growth factor beta required for activation of the p15(Ink4b) G(1) arrest pathway. Mol Cell Biol 1999; 19:5913-22.

15. Elliott RL, Blobe GC. Role of transforming growth factor beta in human cancer. J Clin Oncol 2005;23:2078-93.

16. Boitani C, Stefanini M, Fragale A, Morena AR. Activin stimulates Sertoli cell proliferation in a defined period of rat testis development. Endocrinology 1995;136:5438-44.

17. Miro F, Hillier SG. Modulation of granulosa cell deoxyribonucleic acid synthesis and differentiation by activin. Endocrinology 1996;137:464-8.

18. Chen Y-G, Lui HM, Lin S-L, Lee JM, Ying S-Y. Regulation of cell proliferation, apoptosis, and carcinogenesis by activin. Exp Biol Med (Maywood);227:75-87.

19. Zauberman A, Oren M, Zipori D. Involvement of p21(WAF1/Cip1), CDK4 and Rb in activin A mediated signaling leading to hepatoma cell growth inhibition. Oncogene 1997; $15: 1705-11$.

20. Sehy DW, Shao LE, Yu AL, Tsai WM, Yu J. Activin A-induced differentiation in $\mathrm{K} 562$ cells is associated with a transient hypophosphorylation of RB protein and the concomitant block of cell cycle at $\mathrm{G} 1$ phase. J Cell Biochem 1992;50:255-65. 
21. Gold LI. The role for transforming growth factor-beta (TGF $\beta$ ) in human cancer. Crit Rev Oncog 1999;10:303-60.

22. Lu S-L, Reh D, Li AG, Woods J, Corless CL, Kulesz-Martin M, et al. Overexpression of transforming growth factor $\beta 1$ in head and neck epithelia results in inflammation, angiogenesis, and epithelial hyperproliferation. Cancer Res 2004;64:4405-10.

23. Muraoka-Cook RS, Dumont N, Arteaga CL. Dual role of transforming growth factor beta in mammary tumorigenesis and metastatic progression. Clin Cancer Res 2005:11:937s-43s.

24. Levy L, Hill CS. Alterations in components of the TGF $\beta$ superfamily signaling pathways in human cancer. Cytokine Growth Factor Rev 2006; 17:41-58.

25. Kaklamani VG, Hou N, Bian Y, Reich J, Offit K, Michel LS, et al. TGFBR1*6A and cancer risk: a meta-analysis of seven case-control studies. J Clin Oncol 2003;21:3236-43.

26. Pasche B, Knobloch TJ, Bian Y, Liu J, Phukan S, Rosman D, et al. Somatic acquisition and signaling of TGFBR $1 * 6 \mathrm{~A}$ in cancer. JAMA 2005;294:1634-46.

27. Hahn SA, Schutte M, Hoque AT, Moskaluk CA, da Costa LT, Rozenblum E, et al. DPC4, a candidate tumor suppressor gene at human chromosome 18q21.1. Science 1996;271:350-3.

28. Fleisch MC, Maxwell CA, Barcellos-Hoff MH. The pleiotropic roles of transforming growth factor beta in homeostasis and carcinogenesis of endocrine organs. Endocr Relat Cancer 2006; $13: 379-400$

29. Lazzereschi D, Nardi F, Turco A, Ottini L, D'Amico C, MarianiCostantini R, et al. A complex pattern of mutations and abnormal splicing of Smad4 is present in thyroid tumours. Oncogene 2005:24(34):5344-54.

30. Zhu Y, Richardson JA, Parada LF, Graff JM. Smad3 mutant mice develop metastatic colorectal cancer. Cell 1998;94:703-14.

31. Kawaguchi A, Ikeda M, Endo T, Kogai T, Miyazaki A, Onaya T. Transforming growth factor-beta1 suppresses thyrotropininduced $\mathrm{Na}^{+} / l^{-}$symporter messenger RNA and protein levels in FRTL-5 rat thyroid cells. Thyroid 1997;7:789-94.

32. Morris JC, 3rd, Ranganathan G, Hay ID, Nelson RE, Jiang NS. The effects of transforming growth factor-beta on growth and differentiation of the continuous rat thyroid follicular cell line, FRTL-5. Endocrinology 1988;123:1385-94.

33. Asmis LM, Kaempf J, Von Gruenigen C, Kimura ET, Wagner HE, Studer $\mathrm{H}$. Acquired and naturally occurring resistance of thyroid follicular cells to the growth inhibitory action of transforming growth factor-beta 1 (TGF $\beta$ 1). J Endocrinol 1996;149:485-96.

34. Colletta G, Cirafici AM, Di Carlo A. Dual effect of transforming growth factor beta on rat thyroid cells: inhibition of thyrotropin-induced proliferation and reduction of thyroid-specific differentiation markers. Cancer Res 1989:49:3457-62.

35. Costamagna E, Garcia B, Santisteban P. The functional interaction between the paired domain transcription factor Pax8 and Smad3 is involved in transforming growth factor-beta repression of the sodium/iodide symporter gene. J Biol Chem 2004;279:3439-46.

36. Gartner R, Schopohl D, Schaefer S, Dugrillon A, Erdmann A Toda $S$, et al. Regulation of transforming growth factor beta 1 messenger ribonucleic acid expression in porcine thyroid follicles in vitro by growth factors, iodine, or delta-iodolactone. Thyroid 1997:7:633-40.

37. Cowin AJ, Davis JR, Bidey SP. Transforming growth factorbeta 1 production in porcine thyroid follicular cells: regulation by intrathyroidal organic iodine. J Mol Endocrinol 1992:9:197-205.

38. Holting T, Zielke A, Siperstein AE, Clark OH, Duh OY. Transforming growth factor-beta 1 is a negative regulator for differentiated thyroid cancer: studies of growth, migration, invasion, and adhesion of cultured follicular and papillary thyroid cancer cell lines. J Clin Endocrinol Metab 1994;79:806-13.

39. Ohta K, Pang XP, Berg L, Hershman JM. Antitumor actions of cytokines on new human papillary thyroid carcinoma cell lines. J Clin Endocrinol Metab 1996;81:2607-12.

40. Usa T, Tsukazaki T, Namba H, Ohtsuru A, Kimura H, Villadolid $\mathrm{MC}$, et al. Correlation between suppression of c-myc and antiproliferative effect of transforming growth factor-beta 1 in thyroid carcinoma cell growth. Endocrinology 1994:135:1378-84.
41. Franzen A, Piek E, Westermark B, ten Dijke P, Heldin NE. Expression of transforming growth factor-beta1, activin $A$, and their receptors in thyroid follicle cells: negative regulation of thyrocyte growth and function. Endocrinology 1999; $140: 4300-10$

42. Kotajima A, Miyamoto $Y$, Tsuruo M, Kosaka M, Saito S. Effects of activin A on deoxyribonucleic acid synthesis, iodine metabolism, and cyclic adenosine monophosphate accumulation in porcine thyroid cells. Endocrinology 1995; $136: 1214-8$

43. Schulte KM, Jonas C, Krebs R, Roher HD. Activin A and activin receptors in thyroid cancer. Thyroid 2001:11:3-14.

44. Matsuo SE, Leoni SG, Colquhoun A, Kimura ET. Transforming growth factor-beta 1 and activin A generate antiproliferative signaling in thyroid cancer cells. J Endocrinol 2006:190:141-50.

45. Kimura ET, Kopp P, Zbaeren J, Asmis LM, Ruchti C, Maciel $\mathrm{RM}$, et al. Expression of transforming growth factor $\beta 1, \beta 2$, and $\beta 3$ in multinodular goiters and differentiated thyroid carcinomas: a comparative study. Thyroid 1999;9:119-25.

46. Matsuo SE, Ebina KN, Kulcsar MA, Friguglietti CU, Kimura ET. Activin $\beta B$ expression in rat experimental goiter and human thyroid tumors. Thyroid 2003;13:239-47.

47. Heldin NE, Bergstrom D, Hermansson A, Bergenstrahle $A$, Nakao A, Westermark B, et al. Lack of responsiveness to TGF $\beta 1$ in a thyroid carcinoma cell line with functional type I and type II TGF $\beta$ receptors and Smad proteins, suggests a novel mechanism for TGF $\beta$ insensitivity in carcinoma cells. Mol Cell Endocrinol 1999:153:79-90.

48. Cerutti JM, Ebina KN, Matsuo SE, Martins L, Maciel RM, Kimura ET. Expression of Smad4 and Smad7 in human thyroid follicular carcinoma cell lines. J Endocrinol Invest 2003:26:516-21.

49. Nakao A, Afrakhte M, Moren A, Nakayama T, Christian JL, Heuchel R, et al. Identification of Smad7, a TGF $\beta$-inducible antagonist of TGF $\beta$ signalling. Nature 1997:389:631-5.

50. Afrakhte M, Moren A, Jossan S, Itoh S, Sampath K, Westermark B, et al. Induction of inhibitory Smad6 and Smad7 mRNA by TGF $\beta$ family members. Biochem Biophys Res Commun 1998;249:505-11.

51. Wang T. The 26S proteasome system in the signaling pathways of TGF $\beta$ superfamily. Front Biosci 2003;8:d1109-27.

52. Hershko A, Ciechanover A. The ubiquitin system. Annu Rev Biochem 1998;67:425-79.

53. Hartmann-Petersen R, Seeger M, Gordon C. Transferring substrates to the $26 \mathrm{~S}$ proteasome. Trends Biochem Sci 2003:28:26-31.

54. Ebisawa T, Fukuchi M, Murakami G, Chiba T, Tanaka K, Imamura T, et al. Smurf1 interacts with transforming growth factor-beta type I receptor through Smad7 and induces receptor degradation. J Biol Chem 2001;276:12477-80.

55. Moren A, Imamura T, Miyazono K, Heldin CH, Moustakas A. Degradation of the tumor suppressor Smad4 by WW and HECT domain ubiquitin ligases. J Biol Chem 2005;280:22115-23.

56. Koinuma D, Shinozaki M, Komuro A, Goto K, Saitoh M, Hanyu $A$, et al. Arkadia amplifies TGF $\beta$ superfamily signalling through degradation of Smad7. Embo J 2003;22:6458-70.

57. Ricarte-Filho JCM, Kimura ET. Expressão gênica e imunohistoquímica das E3 ubiquitina-ligases SMURF1 e SMURF2 em carcinomas tiroidianos. Arq Bras Endocrinol Metab 2005;49(supl 1):S77.

58. Dumont N, Bakin AV, Arteaga CL. Autocrine transforming growth factor-beta signaling mediates Smad-independent motility in human cancer cells. J Biol Chem 2003;278:3275-85.

Endereço para correspondência:

Edna T. Kimura

Instituto de Ciências Biomédicas

Av. Prof Lineu Prestes 1524

05508-900 São Paulo, SP

E-mail: etkimura@usp.br 